\title{
Enactment of Default Point in KMV Model on CMBC, SPDB, CMB, Huaxia Bank and SDB
}

\author{
Feixue Huang (Corresponding author) \\ Faculty of Management and Economics, Dalian University of Technology \\ 2 Ling Gong Road, Dalian 116024, China \\ Tel: +86-411-8470-7210 E-mail: huangfeixue@yahoo.cn \\ Yan $\mathrm{He}$ \\ Faculty of Management and Economics, Dalian University of Technology \\ 2 Ling Gong Road, Dalian 116024, China \\ Tel: +86-411-8470-7210Ｅ-mail: forrof@163.com
}

Received: October 28, $2010 \quad$ Accepted: November 17, 2010 doi:10.5430/ijfr.v1n1p30

The research is financed the funds project under the National Science Foundation under Grant No. 70903011; the Ministry of Education of the PRC for young people who are devoted to the researches of humanities and social sciences under Grant No. 09YJC790025.

\begin{abstract}
This study's objective was to solve the problem that probing default point of KMV in listed bank of China. A new model of default point is constructed, because Chinese listed banks on owing to the existence of non-tradable shares. The using of listed banks in China: CMBC, CMB, SDB, SPDB, HUA XIA BANK in the second half of 2004 to 2007 per annum related stocks and financial data. The model of DPT equal to current liabilities (STD) plus 0.25 Long-term debt (LTD) for CMB, SPDB ,CMBC, HUA XIA BANK; The model of DPT equal to current liabilities (STD) plus 0.75 Long-term debt (LTD) for SPB. At the same time, these models have been tested; the results will pass the test. The new model is feasible for probing default point of KMV in listed bank of China.
\end{abstract}

Keywords: KMV, Default point, Non-tradable shares, Listed bank of China

\section{Introduction}

KMV model was based on option pricing theory put forward by Black, Scholes, (1973) and Merton (1974), and named with the first letters of three KMV's founder Kealhofer, McQuown and Vasicek (KMV). Since the 80s of the 20th century, KMV Corporation had collected information of 3400 public companies and 40,000 non-listed companies of since 1973, and had established a database of enormous enterprise credit information. The expected default frequency (EDF) of Thailand National Bank from June 1993 to December 1997, which was calculated with the application of KMV model, began to increase sharply just before the crisis in the middle of 1997. The same accurate risk estimation was done on Enron, WorldCom Company and UA company, and the same conclusion was reached, that the EDF of the companies above mentioned very sensitively reflected the dramatic fluctuations of the credit risk. In 2000, Gordy compared the non-listed company model developed by KMV and financial ratios method used by German's companies, and found that the KMV model can very accurately analyze the credit quality.

Based on risky debt valuation theory and KMV's research, the default point is generally between the nominal debt amount and current liabilities. The most frequently occurred default point, found by KMV based on the a lot of empirical analysis, is at the point when the value of the company is $50 \%$ greater than or equal to current liabilities, the KMV model's prediction accuracy is sensitive to changes of the point. In particular, the structures of China's Listed Companies, with non-tradable shares for a long time, is different from that of Western countries, and when KMV model is calculated, the equity value (market value) must be involved in. This leads to a distortion of the results if the default point of China's listed banks be calculated with the original KMV model.

Therefore, Chinese scholars studied different methods to solve these two issues of setting the default points and 
converting the non-tradable shares. Lu, Zhao, Liu(2003) proposed the weighted method, that is, equity $=$ share price $\times$ number of shares + book value of equity $\times$ (number of shares - the number of shares in circulation) / total capital; Dong, Xue, Guan (2004) construct a linear regression model in which the stock transfer price is dependent variable and the independent variable is the net asset per share, and the net asset per share is made up with the net asset pricing method, which is a kind of econometric model to estimated the transfer price of state-owned shares and is also a frequently used in the transferring and repurchasing of state-owned shares currently, the regression equation is: $P=a+b X(\mathrm{X}$ is the net assets per share). To determine the value of various parameters in the regression equation and verify the reliability of the equation, relevant data of the 38 state-owned shares with agreement transfer agreement in 2000 and 2001 is selected to do regression analysis, and regression equation is got: $P=1.326+0.53 X$. More representative solution is that based on the completed results of split-share reform, Zhou, Yong (2007) take the average closing price of 10 days on the end of the year and half year divided by 1.3 as the total equity price. Sun, Shen, Luo (2008) selected the auction price, the net assets per share, circulation stock price, earnings per share, return on equity and debt ratio of 37 state-owned shares and corporate shares from 2003 to 2007, to get the linear regression model of non-negotiable price.

Zhang, Yang, Chen (2004) with the reference of non-tradable shares pricing, take the net asset per share as the price of non-tradable shares. And in order to examine the influence of different default point value on the ability of the default distance to measure the credit risk, three situations are discussed:

(1) default point(DP) $=$ current liabilities

(2) default point(DP) $=$ current liabilities $+50 \%$ of the long-term liabilities

(3) default point(DP) $=$ current liabilities $+75 \%$ of long-term liabilities

The results are got that when the DP value is equal to current liabilities; the model had the strongest identification to the ST and non-ST corporation.

Zhai, Zhang, Cao (2007) took 15 listed ST companies and 15 listed non-ST company in 2005 as a research sample, and respectively study the default distance under two conditions of the different pricing methods of non-tradable shares and setting different default point,

(1) Equity value $=$ the number of tradable shares $\times$ market price + the number of non-tradable shares $\times$ (market price $\times$ $22 \%)$

(2) Equity value $=$ the number of tradable shares $\times$ market price + the number of non-tradable shares $\times$ net assets per share;

In order to examine the influence of different default point value on the ability of the default distance to identify the credit risk, three situations are discussed:

(1) $D P T 1=S T D+0.25 L T D$

(2) $D P T 2=S T D+0.5 L T D$

(3) $D P T 3=S T D+0.75 L T D$

The KMV model was tested, and concluded: under the situation of equity value $=$ the number of tradable shares $\times$ market price + the number of non-tradable shares $\times$ net assets per share and $D P T 3=S T D+0.75 L T D$, the default distance (DD) output from KMV model can effectively identify the ST companies and non-ST companies and as time of the company was specially treated (ST) approaches, the recognition ability of model grew up.

In summary, these studies have ignored a separate and specific analysis to listed banking industry with Chinese characteristics. In this paper, under the actual situation of Chinese listed banks, by building a suitable KMV model to calculate the default point is proposed. By using the half-yearly related stock data and financial data during the first half of 2003 to 2008 of five representative listed Banks in China: China Merchants Bank (CMB), Shanghai Pudong Development Bank (PDB), China Minsheng Banking (Minsheng), Shenzhen Development Bank (Shenfa), Huaxia Bank (Huaxia), the empirical testing is done with the amended KMV model, and then the empirical results is compared with that of the KMV model with a self-formed default point. Therefore the default point calculation model consistent with the listed bank in China is established.

\section{Methods and process}

\subsection{Calculation method of KMV Risk model}

The first step, according to assumptions of KMV model, the capital structure is formed by equity, short-term liabilities that is equivalent to cash, long-term liabilities that is considered sustainable pension and convertible preferred stock. In 
this assumption, according to the classic Black - Scholes - Merton [2] model, the option valuation model when sold had similarity with the default option; the current market value of the risk loans depends on 5 variables:

The value of defaults option of a risk loan is

$$
\begin{aligned}
& \mathrm{E}=f\left(V, B, r, \sigma_{V}, \tau\right) \\
& f\left(V, \sigma_{V}\right)=E=V \times N\left(d_{1}\right)-B \times e^{-r t} \times N\left(d_{2}\right) \\
& d_{1}=\frac{\ln \left(\frac{V}{B}\right)+\left(r+\frac{1}{2} \times \sigma_{V}^{2}\right) \tau}{\sigma_{V} \sqrt{\tau}} \\
& d_{2}=d_{1}-\sigma_{V} \sqrt{\tau}
\end{aligned}
$$

In equation (2): $\mathrm{V}$ is the value of assets market, $\mathrm{B}$ is the loan price, $\mathrm{r}$ the risk free rate, ${ }^{\sigma_{s}}$ and $^{\sigma_{V}}$ were the market value of equity and volatility of the asset market respectively. $\tau$ is the expiration date for the put option, in the case of loans, it is the time limits (or the default time limits), $\mathrm{N}(\mathrm{d})$ is the cumulative probability distribution function.

According to the relationship between the volatility of the company's equity value ${ }^{\sigma_{S}}$ hat can be observed and the volatility of the company's assets value that can not be observed, the function is established:

$$
\sigma_{S}=g\left(\sigma_{V}\right)=\frac{V \times N\left(d_{1}\right) \times \sigma_{V}}{E}
$$

In equation (2) and (5), there are two unknown variables, the $\mathrm{V}$ and $\sigma_{V}$ are obtained by continuous iteration.

Second step, how to determine the default point (DPT). Based on the empirical analysis of a large number of default facts, KMV found the critical point of the most frequently occurred defaults is at the point when the company value is greater than or is equal to the sum of $50 \%$ current liabilities and $100 \%$ long-term liabilities. Setting: CL for short-term liabilities; LL for long-term liabilities:

$$
D P T=C L+0.5 L L
$$

The third step, to estimate the default distance (DD). Default distance is the relative distance the assets value falling down from the current level to the default point within the risk period, and the default distance can be also expressed as the standard variance of the future assets expectation and the assets at the default point. It can be an indicator to measure the default risk and can compare the different companies. Default distance:

$$
D D=\frac{E(V)-D P T}{E(V) \times \sigma_{V}}
$$

The fourth step, to estimate the expected default probability (EDF) of a company. The expected default frequency (EDF) in the KMV model is determined by the mapping relation between the default distance (DD) and the expected default frequency (EDF). Therefore, to establish the mapping relation is the prerequisite to determine the expected default rate. However, due to the current deficient credit system in China, as there is a serious lack of the statistical data of the historical corporate default or bankruptcy, it is difficult to convert the default distance into the actual default rate and to calculate the expected default probability (EDF). Nevertheless, the unique mapping relation between the default distance (DD) and the expected default frequency (EDF) exists, which means the length of the default distance can reflect the credibility of one company to some extent. Therefore, in this article distance default (DD) replace the expected default frequency (EDF).

\subsection{The model to calculate the default point in $K M V$}

According to the risk debt valuation theory and KMV's research, the default point is generally at some point between the total liabilities and the current liabilities. Based on the research in which the default point is at the point when the company value is equal to the sum of current liabilities and 50\% long-term liabilities, in order to measure under different default points different default distance identifying the credit risks of listed banks, the formula setting the default point is amended by adding two different conditions that the default point is equal to the sum of $25 \%$ current liabilities and long-term debt and the default point is equal to the sum of current liabilities and $75 \%$ long-term liabilities both cases. The formula was STD - short-term liabilities, and LTD - long-term liabilities respectively:

$$
\begin{aligned}
& D P T 1=S T D+0.25 L T D \\
& D P T 2=S T D+0.5 L T D \\
& D P T 3=S T D+0.75 L T D
\end{aligned}
$$




\section{Empirical results and analysis}

\subsection{Data sources and preprocessing}

Based on asset size and listing time of listed banks in Shanghai and Shenzhen stock markets, CMBC, CMB, SDB, SPDB, HUA XIA BANK are selected due to their high proportion of total bank assets and broad influence. The sample data is the half year financial data from 2004 to 2008, which is available until 2008 and Hua Xia Bank was listing on September 12, 2003. The Stock market data is from the GAT Research Service Center: (http://www.gtarsc.com/Components/default.aspx), in which the comparable prices taking into the account of cash dividend re-investment is adopted as the stock closing price, and the influence of halted days is not considered. Relevant financial data and non-tradable shares number respectively comes from the semiannual Bank reports and annual reports. The risk-free rate is obtained from the calculation with default distance on the treasury bonds issued by Finance Ministry of PRC and more than six months less than one year, as shown in Table 1:

\subsection{Empirical process and results}

(1) Successive iteration method is used to calculate the value of the assets and its volatility according to stock values, stock price volatility and the book liabilities value of the company. Firstly the stock volatility is calculated, under the assumption that stock prices conform the lognormal distribution, the daily return rate of equity is:

$$
u_{i}=\operatorname{In}\left(S_{i} / S_{i-1}\right)
$$

in formula (11), $S_{i} / S_{i-1}$ is the relative daily price for the stock, which taking into the account of cash dividend re-investment, and the available opening price is calculated. The stock daily return as follows:

$$
\sqrt{\frac{1}{n-1} \sum_{i=1}^{n}\left(u_{i}-\bar{u}\right)^{2}}
$$

Where: $\bar{u}$ is the mean of $u$. Stock trading days are $\mathrm{N}$ half year, the relationship of the annual earnings volatility $\sigma_{s}$ and daily return volatility $\mathrm{S}$ is:

Equations (2) and (5) are nonlinear equations, in this paper calculation software Matlab6.5 use programs to calculate value of assets $\mathrm{V}$ and asset value volatility $\sigma_{V}$ according to equations (2) - (6), the time is half year.

(2) Calculate the default point and the default distance (DD)

The half-yearly default point DPT1, DPT2, DPT3 of CMBC, CMB, SDB, SPDB, HUA XIA BANK from the latter half year of 2003 to that of 2007were calculated according to the formula (8), (9), (10); Then corresponding default distance DD1, DD2, DD3 were calculated with formula (7). The results shown in Table 2:

\subsection{Empirical results analysis}

Table 2 is the estimation results of default point based on amended model. First the market assets and its volatility are obtained by using MATLAB6.5, and then the default distance to measure the credit risk condition is got with formula (7). One of the credit risk evaluation criteria of the five listed banks in KMV model is to spread out the results of default distance as far as possible. According to statistical theory, it can be more sensitive to reflect the differences by using their variance. With a bigger variance, the data has a bigger difference and with a smaller variance the data is more focused. In this article independent samples T test of SPSS is also used to test the results of five banks, and by comparing the test results the applicability in distinguishing the credit risk of the default distance calculated with three amended KMV models is examined. In this way, the best amended model is selected as it can be better applied to the commercial growth banks in China.

\subsubsection{Variance test}

The variance of default distance every half year during 2004-2 008 under three settled default points is got, and then compare them. With a bigger value the default distance is not focused closely and it can be more sensitive to distinguish the credit risk of five among banks. Table 3 is the variance results:

From the value of $\mathrm{R}$ square shown in Table 3, in addition to the second half year of 2004 and the second half year of 2007, the variances of the five banks calculated with $D P T 1=S T D+0.25 L T D$ are bigger than that calculated with $D P T 1=S T D+0.5 L T D, D P T 1=S T D+0.75 L T D$. It Shows when the default point settings at the point which equals to the sum of current liabilities and 25\% long-term liabilities, the amended KMV model is most suitable for the practice of China and the five banks. 


\subsection{2. $T$ test}

$\mathrm{T}$ test was used to test three ways $\mathrm{T}$ test results of five listed banks from 2004 to 2008 . With SPSS16, because the value of the default distance is not available at first, 0 is taken as the default value, with $95 \%$ confidence interval. The results shown in Table 4:

From the results in table 4, the T test results of CMBC, CMB, SPDB, HUA XIA BANK are identical: the best $\mathrm{T}$ test result is under the condition of $D P T 1=S T D+0.25 L T D$, and only the best $\mathrm{T}$ test results of SDB is under the condition of $D P T 3=S T D+0.75 L T D$. Compare the long and short term liability of five banks to explain why SDB is different from the other four banks, as shown in table 5:

From the Table 5, it can be seen that the ratios of short-term liabilities to long-term liabilities of CMBC, CMB, SPDB, HUA XIA BANK change a little, while that of SDB changes. Because the default point is at some place between the total liability and the current liability, the forecasting accuracy is sensitive to the change of the default point, and the ratios of short-term liabilities to long-term can reflect the expected credit risk to some extent, the ratio is very important in calculating the default point. The irregular change of SDB leads to the difference with the other four banks.

From above, the model to calculate the default point is:

$$
D P T 1=S T D+0.25 L T D(\mathrm{CMB}, \mathrm{CMB}, \mathrm{SPDB}, \mathrm{HXB})
$$

$D P T 3=S T D+0.75 L T D(\mathrm{SDB})$

\section{Conclusions}

The KMV model, widely be used in mature markets abroad, less depend on the financial data, can take advantage of publicly update of stock data to update the model results, with less variables and the efficient market hypothesis is not required. So it can also widely be use in China with distorted accounting information. It especially has application value to the listed China banks whose econometric models require a timely data updating and closing following of the market. But as the KMV model is established originally under the abroad economic environment, the setting of the default point has a big influence on the model's accuracy. Therefore the setting of the default point must be suitable for listed commercial banks in China, and in this paper the default point is settled for growth commercial banks in China.

And an empirical test results show that: When calculating credit risk of Chinese listed banks with KMV model, the default point should be amended as: for CMBC, CMB, SPDB, HUA XIA BANK, the default point equals to the sum of current liabilities and 25\% long-term liabilities; for SDB, the default point equals to the sum of current liabilities and $75 \%$ long-term liabilities. At these points, the default distance can better distinguish the level of credit risk of listed banks. This indicates that when using of KMV model to assess the credit risk of five banks, the amended model presented in this paper to calculate the default point is feasible.

\section{References}

Campi, L., Polbennikov, S., \& Sbuelz, A. (2009). Systematic equity-based credit risk: A CEV model with jump to default, Journal of Economic Dynamics and Control, 33, 93-108.

Dong, Ying-ying, Xue, Feng \& Guan, Wei. (2004).KMV model's applicability in the Chinese Stock Market Analysis and Improvement, PRODUCTIVITY RESEARCH, 8,116-117, 184.

Fischer, B. ,\& Myron, S. (1973).The Pricing of 0ptions and Corporate Liabilities, Journal of Political Economy, 81, 637-654.

Gordy, M.B. (2000). A Comparative Anatomy of Credit Risk Models, Journal of Banking and Finance, 1,119-149.

Grundke, P. (2009). Importance sampling for integrated market and credit portfolio models, European Journal of Operational Research, 19, 206-226.

Kiefer, N. M. (2009).Default estimation for low-default portfolios, Journal of Empirical Finance, 16, 164-173.

Ly, Wei, Zhao, Heng-yan \& Liu, Ji-yun (2003). The Conjecture about the Relation Function of KMV and the Validation at Chinese Stock Market, OPERATIONS RESEARCH AND MANAGEMENT SCIENCE, 12, 43-48.

Merton, R.C. (1974).On the pricing of corporate debt: the risk structure of interest rates, The Journal of Finance, 29, 449-470.

Norden, L \& Wagner, W. (2008).Credit derivatives and loan pricing, Journal of Banking \& Finance, 32,2560-2569.

Sun, Xiao-yan, Shen, Yue \& Luo, Lu-qi (2008).Empirical Study on Value Evaluation of Chinese Public Offering 
Companies Based on KMV Model, JOURNAL OF INDUSTRIAL ENGINEERING AND ENGINEERING MANAGEMENT, 22, 102-108.

Totouom, D. \& Armstrong, M. (2008).Credit risk dependence modeling with dynamic copula: An application to CDO tranches, Advances in Econometrics: Econometrics and Risk Management, 22, 85-102.

Zai, Dong-sheng, Zhang, Juan \& Cao, Yun-fa (2007). KMV model in listed companies application of credit risk management, INDUSTRIAL TECHNOLOGY \& ECONOMY, 26, 126-127,134.

Zhou, Zhao-xiong (2004). An Application of KMV Model in Credit Risk Evaluation of Public Companies, SYSTEMS ENGINEERING, 22, 84-89.

Zhou, Zi-yuan \& Yang Yong-sheng (2007). Using the Distance to Default to Identify Credit Risks: An Empirical Study, AUDIT \& ECONOMY RESEARCH, 22, 81-85.

Table 1. PRC Ministry of Finance issued six months less than one year bonds interest rate in the distance period (\%)

\begin{tabular}{|c|c|c|c|c|c|c|c|c|c|c|}
\hline & $2004-\mathrm{f}$ & $2004-1$ & $2005-\mathrm{f}$ & $2005-1$ & $2006-\mathrm{f}$ & $2006-1$ & $2007-\mathrm{f}$ & $2007-1$ & $2008-\mathrm{f}$ & $2008-1$ \\
\hline $\mathrm{R}$ & 0.72 & 0.72 & 0.72 & 0.72 & 0.72 & 0.72 & 0.72 & 0.81 & 0.72 & 0.72 \\
\hline
\end{tabular}

Data source: Yearly Treasury issued Notice of PRC; -f means the first half year;-1 means the latter half year.

Table 2. DPT and DD results of CMB, SPDB, HUA XIA BANK, CMBC, SDB unit: DPT (billion RMB)

\begin{tabular}{|c|c|c|c|c|c|c|c|c|c|c|c|}
\hline & & 2004-f & 2004-1 & $2005-\mathrm{f}$ & $2005-1$ & 2006-f & 2006-1 & $2007-f$ & $2007-1$ & $2008-f$ & $2008-1$ \\
\hline \multirow[t]{6}{*}{ CMB } & DPT1 & 4968.7 & 5559.3 & 6204.3 & 6714.7 & 7735.1 & 8646.4 & 10308.1 & 12281.1 & 13069.3 & 14618.1 \\
\hline & DD1 & 5.1852 & 1.4749 & 4.8146 & 1.3772 & 4.2284 & 3.9468 & 2.6382 & 3.0257 & 2.5083 & 1.9733 \\
\hline & DPT2 & 5043.9 & 5645.8 & 6300.1 & 6840.9 & 7794.7 & 8694.1 & 10370.5 & 12329.3 & 13107.2 & 14718.8 \\
\hline & DD2 & 5.1906 & 1.4738 & 4.8172 & 1.346 & 4.247 & 3.944 & 2.636 & 3.022 & 2.5064 & 1.9726 \\
\hline & DPT3 & 5119.1 & 5732.3 & 6395.9 & 6967.0 & 7854.4 & 8741.7 & 10433.0 & 12377.5 & 13145.1 & 14819.5 \\
\hline & DD3 & 5.1969 & 1.4734 & 4.7834 & 1.3429 & 4.2410 & 3.9418 & 2.6341 & 3.0239 & 2.5088 & 1.9732 \\
\hline \multirow[t]{6}{*}{ SPDB } & DPT1 & 2908.1 & 3243.2 & 3461.6 & 4030.1 & 5995.9 & 6440.1 & 7299.1 & 8669.9 & 9548 & 12536.2 \\
\hline & DD1 & 4.8158 & 5.2405 & 4.0053 & 4.9797 & 3.0550 & 3.1795 & 2.3774 & 2.9135 & 2.0383 & 1.8476 \\
\hline & DPT2 & 3276.8 & 3635.6 & 3902.1 & 4545.2 & 6041.2 & 6485.8 & 7344.2 & 8735.6 & 9592 & 12583.2 \\
\hline & DD2 & 4.7733 & 5.1736 & 3.9524 & 4.9257 & 3.056 & 3.613 & 2.378 & 2.917 & 2.0395 & 1.8464 \\
\hline & DPT3 & 230.4 & 217.7 & 213.4 & 234.6 & 259.6 & 354.7 & 629.3 & 1675.5 & 9636 & 12630.2 \\
\hline & DD3 & 4.7673 & 5.1642 & 3.9248 & 4.8822 & 3.0568 & 3.1748 & 2.3789 & 2.9138 & 2.0396 & 1.8433 \\
\hline \multirow{6}{*}{$\begin{array}{l}\mathrm{H} \\
\mathrm{X} \\
\mathrm{B}\end{array}$} & DPT1 & 2226.9 & 2499.7 & 2667.4 & 2988.8 & 3752.5 & 4271.2 & 4598.9 & 5585.9 & 5957.6 & 6863.1 \\
\hline & DD1 & 5.0207 & 4.5711 & 4.5766 & 5.6655 & 5.5372 & 3.4373 & 2.0959 & 2.3585 & 2.0266 & 1.8384 \\
\hline & DPT2 & 2339.8 & 2648.8 & 2825.3 & 3144.8 & 3771.5 & 4292.1 & 4629.3 & 5654.8 & 6017.3 & 6922.8 \\
\hline & DD2 & 4.9941 & 4.5635 & 4.5549 & 5.6404 & 5.6248 & 3.4669 & 2.1446 & 2.4159 & 2.03 & 1.8362 \\
\hline & DPT3 & 2452.7 & 2798.0 & 2983.2 & 3300.8 & 3790.5 & 4313.1 & 4659.7 & 5723.8 & 6077 & 6982.5 \\
\hline & DD3 & 4.9872 & 4.5415 & 4.5158 & 5.6413 & 5.5581 & 3.4331 & 2.0931 & 2.3527 & 2.0259 & 1.8411 \\
\hline \multirow[t]{6}{*}{ CMBC } & DPT1 & 3136.1 & 3424.3 & 3722.4 & 4343.5 & 4751.3 & 5951.0 & 6624.3 & 7798.4 & 9816 & 9741.8 \\
\hline & DD1 & 4.8582 & 2.3109 & 4.6900 & 3.8675 & 2.5139 & 3.9399 & 3.3175 & 2.3879 & 2.4984 & 2.3199 \\
\hline & DPT2 & 3596.0 & 3923.2 & 4557.4 & 4973.1 & 5996.8 & 6686.7 & 7896.2 & 8504.7 & 9900.6 & 9826.8 \\
\hline & DD2 & 2.3068 & 4.6827 & 3.8604 & 2.5040 & 3.9400 & 3.3250 & 2.3850 & 3.2020 & 2.4937 & 2.321 \\
\hline & DPT3 & 3767.7 & 4124.1 & 4771.3 & 5195.0 & 6042.5 & 6749.0 & 7994.0 & 8600.4 & 9985.2 & 9911.8 \\
\hline & DD3 & 2.2934 & 4.6544 & 3.8392 & 2.4883 & 3.9395 & 3.3134 & 2.3832 & 3.2056 & 2.4958 & 2.3192 \\
\hline \multirow[t]{6}{*}{ SDB } & DPT1 & 1883.0 & 1884.9 & 1930.3 & 2114.8 & 2370.7 & 2529.9 & 3047.7 & 3382.5 & 4200.3 & 4520.7 \\
\hline & DD1 & 4.2937 & 5.3426 & 2.8950 & 4.5859 & 3.2004 & 3.5665 & 2.3641 & 2.6488 & 2.133 & 2.0201 \\
\hline & DPT2 & 1918.5 & 1921.2 & 1972.3 & 2157.1 & 2371.3 & 2533.6 & 3053.0 & 3386.8 & 4216.5 & 4540.6 \\
\hline & DD2 & 4.293 & 5.338 & 2.881 & 4.591 & 3.199 & 3.561 & 2.366 & 2.646 & 2.134 & 2.0233 \\
\hline & DPT3 & 1954.0 & 1957.6 & 2014.2 & 2199.4 & 2371.8 & 2537.3 & 3058.3 & 3391.1 & 4232.6 & 4560.5 \\
\hline & DD3 & 4.2658 & 5.3319 & 2.8883 & 4.5452 & 3.2001 & 3.5560 & 2.3680 & 2.6477 & 2.1343 & 2.0203 \\
\hline
\end{tabular}

Notes:-f means the first half year; -1 means the latter half year.

Data source: Author sorting and computing 
Table 3. Five listed banks' three ways default distance variance from 2004 to 2008

\begin{tabular}{|l|l|l|l|l|l|l|l|l|l|l|}
\hline & $2004-\mathrm{f}$ & $2004-1$ & $2005-\mathrm{f}$ & $2005-1$ & $2006-\mathrm{f}$ & $2006-1$ & $2007-\mathrm{f}$ & $2007-1$ & $2008-\mathrm{f}$ & $2008-1$ \\
\hline$R^{2}(D P T 1)$ & 1.113 & $\mathbf{3 . 1 6 8}$ & $\mathbf{0 . 6 2 5 1}$ & $\mathbf{3 . 7 3 2 1}$ & $\mathbf{1 . 4 3 1 7}$ & $\mathbf{0 . 1 0 9 8}$ & $\mathbf{0 . 2 1 6 8}$ & 0.0907 & $\mathbf{0 . 0 7 9}$ & $\mathbf{0 . 0 7 8}$ \\
\hline$R^{2}(D P T 2)$ & 1.368 & 2.5074 & 0.5622 & 3.2454 & 1.0591 & 0.0529 & 0.0303 & 0.0969 & 0.087 & 0.068 \\
\hline$R^{2}(D P T 3)$ & 1.381 & 2.4907 & 0.5367 & 3.2182 & 1.0047 & 0.0855 & 0.0367 & 0.1117 & 0.068 & 0.058 \\
\hline
\end{tabular}

Notes:-f means the first half year; -l means the latter half year.

Data source: Author sorting and computing

Table 4. Five listed banks'three ways T test results from 2004 to 2008

\begin{tabular}{|c|c|c|c|c|c|}
\hline & CMB & SPDB & HUA XIA & CMBC & SDB \\
\hline $\mathrm{T}_{1}$ (DPT1) & $\mathbf{6 . 4 7 6}$ & $\mathbf{1 2 . 4 4 2}$ & $\mathbf{1 0 . 3 6 7}$ & $\mathbf{9 . 9 6 8}$ & 5.862 \\
\hline $\mathrm{T}_{2}$ (DPT2) & 6.341 & 12.343 & 10.156 & 9.95 & 15.893 \\
\hline $\mathrm{T}_{3}$ (DPT3) & 6.233 & 12.238 & 10.246 & 9.652 & $\mathbf{1 6 . 0 0 9}$ \\
\hline
\end{tabular}

Data source: Author sorting and computing

Table 5 Five listed banks' short-term liabilities long-term liabilities ratio

\begin{tabular}{|l|c|c|c|c|c|c|c|c|c|c|}
\hline & $2004-f$ & $2004-1$ & $2005-f$ & $2005-1$ & $2006-f$ & $2006-1$ & $2007-f$ & $2007-1$ & $2008-f$ & $2008-1$ \\
\hline CMBC & 4.74 & 4.38 & 4.83 & 5.11 & 32.28 & 26.29 & 19.68 & 21.71 & 28.74 & 28.4 \\
\hline SPDB & 1.72 & 1.82 & 1.71 & 1.71 & 32.88 & 34.98 & 40.15 & 32.78 & 54 & 66.43 \\
\hline SDB & 13.02 & 12.7 & $\mathbf{1 1 . 2 6}$ & $\mathbf{1 2 . 2 5}$ & $\mathbf{1 1 1 6 . 5}$ & $\mathbf{1 6 9 . 9 8}$ & $\mathbf{1 4 3 . 5 9}$ & $\mathbf{1 9 7 . 8 9}$ & 64.67 & 56.51 \\
\hline CMB & 16.3 & 15.8 & 15.9 & 13.1 & 32.2 & 45.1 & 41 & 63.5 & 85.98 & 36.04 \\
\hline $\begin{array}{l}\text { HUA } \\
\text { XIA }\end{array}$ & 4.68 & 3.94 & 3.97 & 4.54 & 49.23 & 50.64 & 37.59 & 19.99 & 24.71 & 28.5 \\
\hline
\end{tabular}

Notes:-f means the first half year;-l means the latter half year; the results are calculate by short-term liabilities/ long-term liabilities; Data source: the semiannual and annual reports.

Data source: Author sorting and computing 